\title{
Severe acute respiratory coronavirus virus 2 (SARS-CoV-2) IgG results among healthcare workers in a rural upstate New York hospital system
}

\author{
Wendy M. Brunner $\mathrm{PhD}^{1}$ (1), Liane Hirabayashi MA², Nicole L. Krupa BS¹, Melissa B. Scribani MPH${ }^{1}$, Paul Jenkins PhD ${ }^{1}$, \\ Stephen D. Clark BS ${ }^{1}$, John J. May MD ${ }^{1,2}$ and Anne M. Gadomski MD, MPH ${ }^{1}$ \\ ${ }^{1}$ Research Institute, Bassett Medical Center, Cooperstown, New York and ${ }^{2}$ Northeast Center for Occupational Health and Safety, Bassett Medical Center, \\ Cooperstown, New York
}

To the Editor - To better understand the effectiveness of occupational infection control measures during the coronavirus disease 2019 (COVID-19) pandemic, we surveyed and antibody tested employees of Bassett Healthcare Network, located in rural upstate New York, 200 miles northwest of New York City. Employer-sponsored SARS-CoV-2 IgG antibody testing was conducted from May 4 to 29,2020 . Network leadership prioritized employees with a high likelihood of exposure to COVID-19-infected patients. A 21.7\% random sample of employees was also included for antibody testing to ensure that our seroprevalence estimate was representative of all network employees.

The study questionnaire captured demographics, COVID-19 polymerase chain reaction (PCR) status, potential COVID-19 work and nonwork exposures, and COVID-19 symptoms experienced since January 1, 2020 (based on the Centers for Disease Control and Prevention's case report form). The recall period for exposure questions (March 1-May 31, 2020) coincided with New York State's stay-at-home order plus 2 weeks.

We compared seroprevalence among employees to that for patients tested during the same period. Employee serology testing was performed by Bassett Medical Center Laboratory using the SARS-CoV-2 IgG Abbott Architect assay (Abbott Laboratories, Abbott Park, IL), with $100 \%$ sensitivity and $99.6 \%$ specificity. ${ }^{1}$ IgG level $\geq 1.40$ was defined as positive. Most serology testing for patients (96\%) was conducted by the Mayo Clinic using the VITROS AntiSARS-CoV-2 IgG Test (Ortho-Clinical Diagnostics, Linden, NJ), with $90.0 \%$ sensitivity and $100 \%$ specificity. ${ }^{2}$ The remaining patient tests were conducted by the in-house laboratory using the Abbott test.

We compared questionnaire responses by antibody status using $\chi^{2}$ tests for categorical variables and $t$ tests for continuous variables. Analyses were conducted using SAS version 9.3 software (SAS Institute, Cary, NC). This study was approved by the Mary Imogene Bassett Institutional Review Board.

\section{Results}

Among 764 employees tested, 15 were positive for SARS-CoV-2 IgG antibodies, for a seroprevalence of $2.0 \%$, compared to $4.5 \%$ for patients (ie, 34 seropositives among 762 tested). Of the 764 employees tested, $601(78.7 \%)$ completed the study questionnaire.

\footnotetext{
Author for correspondence: Wendy M. Brunner, E-mail: wendy.brunner@bassett.org Cite this article: Brunner WM, et al. (2021). Severe acute respiratory coronavirus virus 2 (SARS-CoV-2) IgG results among healthcare workers in a rural upstate New York hospital system. Infection Control \& Hospital Epidemiology, 42: 1397-1400, https:// doi.org/10.1017/ice.2020.1296
}

Seroprevalence among all study participants was 12 of 601 $(2.0 \%)$ and 4 of $130(3.1 \%)$ in the random sample. The mean IgG level was 4.93 (range, 2.10-8.14) among seropositives and 0.06 (range, 0.01-1.17) among seronegatives. One-third of seropositives reported a positive PCR test, $8.3 \%$ reported a negative PCR test, and $58.3 \%$ had no PCR test. Of the 589 seronegative employees, 47 reported having a PCR test (all negative).

Seropositive employees were just as likely as seronegative employees to report having no direct contact with COVID-19 patients $(25.0 \%$ vs $17.7 \% ; P=0.46)$ (Table 1$)$. Seropositive employees were less likely to report involvement in high-risk patientrelated tasks, such as COVID-19 testing, although these differences were not statistically significant.

There were no statistically significant differences by serology status among employees reporting travel outside of the region or social distancing practices. Seropositive employees were more likely than seronegative employees to report having a known or suspected COVID-19 case in their household $(41.7 \%$ vs $10.9 \%$, $P=.0072$ ), and they were just as likely as seronegative employees to report living with an essential services worker who continued to work outside the home $(50.0 \%$ vs $51.4 \% ; P=.53)$. Although more seropositive employees had contact outside of work with a known or suspected COVID-19 contact, this difference was not statistically significant $(41.7 \%$ vs $31.6 \% ; P=.13)$.

Two-thirds of the seropositive employees (66.7\%) reported a COVID-19-like illness since January 1, 2020, compared with $44.9 \%$ of seronegative employees, however this difference was not statistically significant $(P=.13)$. Of the seropositive employees, 4 (33.3\%) were asymptomatic. Among the 258 seronegative employees reporting COVID-19-like illness, 56 stated that their symptoms ended in January or February. Seropositive and seronegative employees showed different profiles in symptoms; seropositive employees were more likely to report sore throat, dry cough, and headache.

\section{Discussion}

Our findings among employees in a rural healthcare network show that direct patient care was not associated with increased likelihood of COVID-19 infection and that seropositivity was more likely associated with nonwork exposures. Similar findings have been reported in urban, densely populated settings and larger medical centers. ${ }^{3-7}$ Although travel, social-distancing practices, and having an essential-services worker in the household did not differ by antibody status in our study, being exposed to a COVID-19 contact

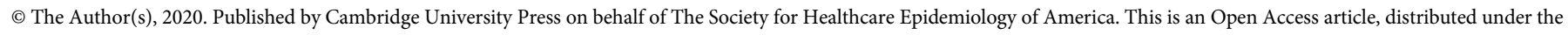

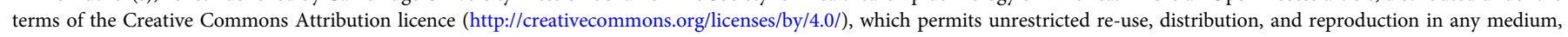
provided the original work is properly cited. 
Table 1. Comparison of Employees With and Without Previous SARS-CoV-2 Infection ( $N=601$ ), Bassett Healthcare Network, May 4-29, 2020

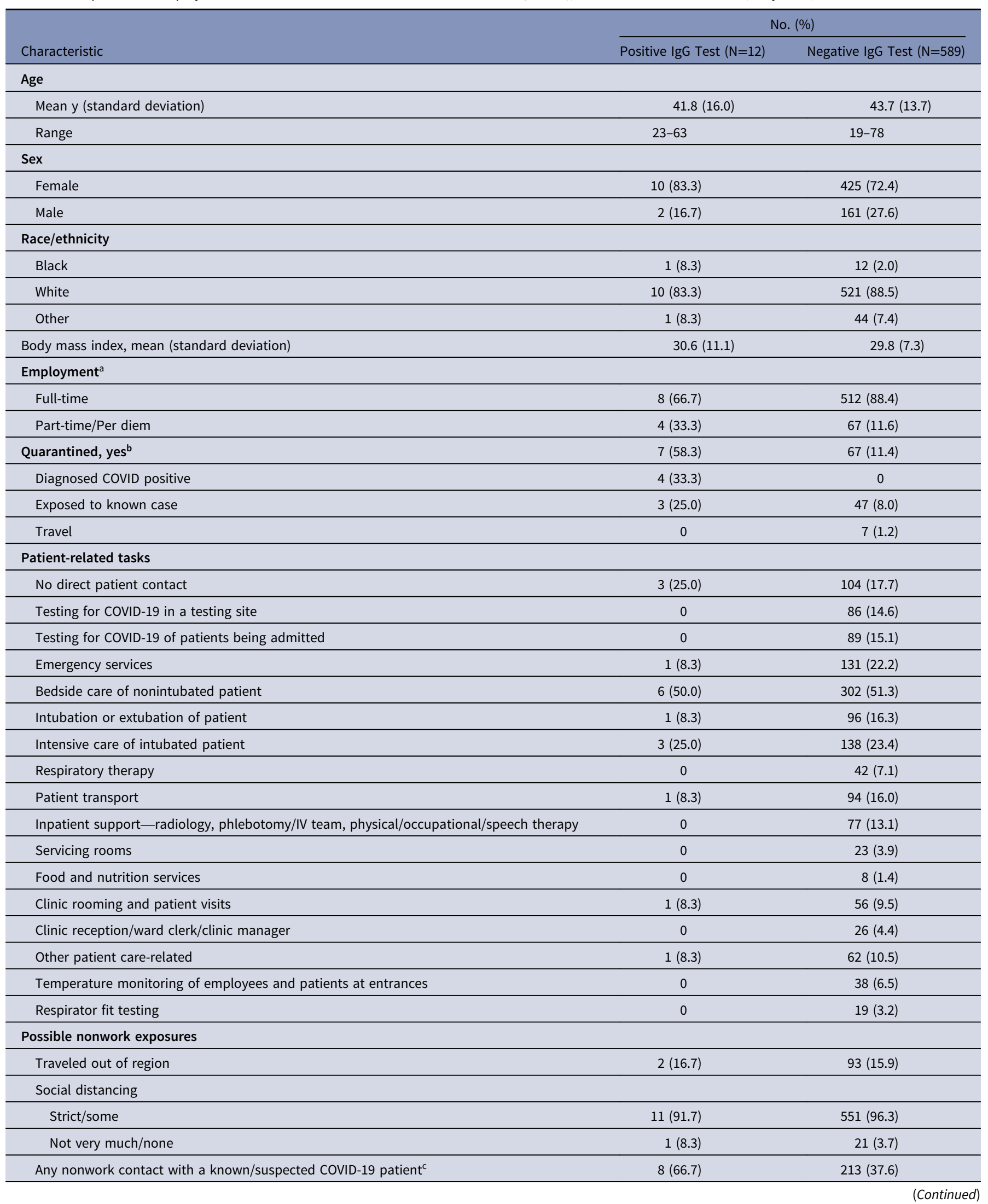


Table 1. (Continued)

\begin{tabular}{|c|c|c|}
\hline \multirow[b]{2}{*}{ Characteristic } & \multicolumn{2}{|c|}{ No. (\%) } \\
\hline & Positive IgG Test $(\mathrm{N}=12)$ & Negative IgG Test $(\mathrm{N}=589)$ \\
\hline Had any contact (within $2 \mathrm{~m}$ for $>15 \mathrm{~min}$ ) with a known/suspected COVID-19 patient & $5(41.7)$ & $181(31.6)$ \\
\hline Known & $4(80.0)$ & $108(60.0)$ \\
\hline Suspected & $1(20.0)$ & $62(34.3)$ \\
\hline Lived with a known/suspected COVID-19 patient ${ }^{d}$ & $5(41.7)$ & $62(10.9)$ \\
\hline Known & $3(60.0)$ & $11(17.7)$ \\
\hline Suspected & $1(40.0)$ & $24(38.7)$ \\
\hline Household includes an essential services person who continued to work outside the home & $6(50.0)$ & $297(51.4)$ \\
\hline \multicolumn{3}{|l|}{ COVID-19-like illness } \\
\hline COVID-19-like illness since January 1, 2020 & $8(66.7)$ & $257(44.9)$ \\
\hline \multicolumn{3}{|l|}{ Symptoms among those reporting COVID-19-like illness } \\
\hline Cough (new onset or worsening of chronic cough) & $6(75.0)$ & $159(61.9)$ \\
\hline Mostly dry cough & $4(80.0)$ & $69(85.2)$ \\
\hline Headache & $6(75.0)$ & $151(58.8)$ \\
\hline Altered sense of smell/taste & $5(62.5)$ & $25(9.7)$ \\
\hline Sore throat & $5(62.5)$ & $152(59.1)$ \\
\hline Fever (documented or subjective) & $4(50.0)$ & $139(54.5)$ \\
\hline Runny nose (rhinorrhea) & $4(50.0)$ & $134(52.4)$ \\
\hline Chills & $3(37.5)$ & $10(42.8)$ \\
\hline Diarrhea & $3(37.5)$ & $54(21.0)$ \\
\hline Exhaustion & $3(37.5)$ & $118(45.9)$ \\
\hline Muscle aches (myalgia) & $3(37.5)$ & $119(46.3)$ \\
\hline Shortness of breath (dyspnea) & $3(37.5)$ & $80(31.1)$ \\
\hline Nausea or vomiting & $2(25.0)$ & $34(13.2)$ \\
\hline Persistent pain or pressure in the chest & $1(12.5)$ & $40(15.6)$ \\
\hline Diagnosed with COVID-19e & $3(37.5)$ & 0 \\
\hline
\end{tabular}

outside of work or in the same household was positively correlated with antibody status.

This study is potentially limited by the timing between COVID-19 exposure and the antibody test. Employees tested $>2-3$ months following COVID-19 infection may no longer have detectable levels of IgG antibodies, thereby underestimating the prevalence of previous employee infection. ${ }^{8-10}$ Other limitations include sampling and recall bias. Employee antibody testing was not done entirely at random; therefore, the estimate of seropositivity reported may not be representative of all employees. Also, seropositive employees may have been more likely to accurately recall potential exposures to COVID-19. Finally, due to the low prevalence of seropositivity, statistical comparisons between seropositive and seronegative employees had limited statistical power.

During government-mandated shelter-in-place orders, SARSCoV-2 IgG seroprevalence among employees in a rural healthcare network was lower than for the community at large. In this rural region, healthcare workers were more likely to be exposed to COVID-19 outside of the workplace than on the job. Thus, it is important that healthcare workers maintain high vigilance regarding potential nonwork exposures as well as healthcare-related patient-care exposures.

Acknowledgments. We thank the following: Bassett Healthcare Network employee participants, Valerie Bush, Emily Converse, Michelle Cummings, Amanda Fink, Melinda Hasbrouck, Carleen Henderson, Tom Hohensee, Caitlin Liberati, Pamela McCabe, Sandra Mortensen, Melissa Roberts, Aletha Sprague, Jennifer Victory and Tim Williammee.

Financial support. No financial support was provided relevant to this article.

Potential conflicts of interest. All authors report no conflicts of interest relevant to this article.

\section{References}

1. Bryan A, Pepper G, Wener MH, et al. Performance characteristics of the Abbott Architect SARS-CoV-2 IgG assay and seroprevalence in Boise, Idaho. J Clin Microbiol 2020;58(8). doi: 10.1128/JCM.00941-20. 
2. Theel ES, Harring J, Hilgart H, Granger D. Performance characteristics of four high-throughput immunoassays for detection of IgG antibodies against SARS-CoV-2. J Clin Microbiol 2020;58(8):e01243-20.

3. Garcia-Basteiro AL, Moncunill G, Tortajada M, et al. Seroprevalence of antibodies against SARS-CoV-2 among healthcare workers in a large Spanish reference hospital. Nat Commun 2020;11:3500.

4. Morcuende M, Guglielminotti J, Landau R. Anesthesiologists' and intensive care providers' exposure to COVID-19 infection in a New York City academic center: a prospective cohort study assessing symptoms and COVID-19 antibody testing. Anesth Analg 2020. doi: 10.1213/ANE.0000000000005056.

5. Korth J, Wilde B, Dolff S, et al. SARS-CoV-2-specific antibody detection in healthcare workers in Germany with direct contact to COVID-19 patients. J Clin Virol 2020;128:104437. doi: 10.1016/j.jcv.2020.104437.

6. Steensels D, Oris E, Coninx L, et al. Hospital-wide SARS-CoV-2 antibody screening in 3056 staff in a tertiary center in Belgium. JAMA 2020;324: 195-197.
7. Dimcheff DE, Schildhouse RJ, Hausman MS, et al. Seroprevalence of severe acute respiratory syndrome coronavirus-2 (SARS-CoV-2) infection among VA healthcare system employees suggests higher risk of infection when exposed to SARS-CoV-2 outside of the work environment. Infect Control Hosp Epidemiol 2020 [Epub ahead of print]. doi: 10.1017/ice. 2020.1220.

8. Liu J, Guo J, Xu Q, Cai G, Chen D, Shen Y. Detection of IgG antibody during the follow-up in patients with COVID-19 infection. Crit Care 2020;24:448.

9. Patel MM, Thornburg NJ, Stubblefield WB, et al. Change in antibodies to SARS-CoV-2 over 60 days among health care personnel in Nashville, Tennessee. JAMA 2020. doi: 10.1001/jama.2020.18796.

10. Ibarrondo FJ, Fulcher JA, Goodman-Meza D, et al. Rapid decay of antiSARS-CoV-2 antibodies in persons with mild COVID-19. N Engl J Med 2020;383:1085-1087.

\title{
Surveillance study of asymptomatic and presymptomatic coronavirus disease 2019 (COVID-19) in care homes in Northern Ireland
}

\author{
Claire Neill MPH, MFPH${ }^{1}$, Muhammad Sartaj MPH, FFPH ${ }^{1}$, Lorna Holcroft MBBS ${ }^{1}$, Syed Shahzad Hasan $\mathrm{PhD}^{2}$, \\ Barbara R. Conway $\mathrm{PhD}^{2}$ and Mamoon A. Aldeyab $\mathrm{PhD}^{2}$ (1) \\ ${ }^{1}$ Public Health Agency, Belfast, Northern Ireland and ${ }^{2}$ Department of Pharmacy, School of Applied Sciences, University of Huddersfield, Huddersfield, \\ United Kingdom
}

To the Editor-Recent studies have highlighted the potential for transmission of severe acute respiratory syndrome coronavirus 2 (SARS-CoV-2) from individuals who are symptomatic, presymptomatic, and asymptomatic of infection. ${ }^{1-3}$ This is of particular concern in high-risk settings, such as long-term care facilities. Care-home residents may be more vulnerable to infection with an increased likelihood of risk factors, including age and pre-existing comorbidities. ${ }^{4,5}$ Differentiating asymptomatic from presymptomatic infection and the range of possible symptoms associated with coronavirus disease 2019 (COVID-19) in different populations remains of interest. The potential for an atypical presentation of COVID-19 in care-home residents has been reported. ${ }^{6}$ This study was conducted to identify the rate of asymptomatic and presymptomatic COVID-19 in care-home residents and staff, within settings where recent cases of COVID-19 had been identified, including potential atypical presentations of those testing positive for the virus.

This is a report on the results of an outbreak investigation that was conducted as part of public health practice to manage the outbreak, to support the wider public health surveillance, and to inform policy decisions regarding SARS-CoV-2 testing in care homes. As such, the work did not require Research Ethics

Author for correspondence: Dr Mamoon Aldeyab, E-mail: m.aldeyab@hud.ac.uk Cite this article: Neill C, et al. (2021). Surveillance study of asymptomatic and presymptomatic coronavirus disease 2019 (COVID-19) in care homes in Northern Ireland. Infection Control \& Hospital Epidemiology, 42: 1400-1402, https://doi.org/ $10.1017 /$ ice.2020.1284
Committee approval, which is in keeping with the UK Health Research Authority's guidance.

This prospective study with a follow-up review on day 7 was carried out in 5 care homes reporting recent outbreaks of COVID-19 to the Public Health Agency in Northern Ireland. If an individual was symptomatic at the time of sampling, or if they had been symptomatic within the 14 days prior to the test, it was recorded. These data included typical symptoms of cough, fever, or shortness of breath, as well as any atypical symptoms: sore throat, sneezing, nasal discharge/congestion, wheeze, hoarseness, chest pain, acute deterioration, malaise, nausea, confusion, dizziness, diarrhoea, myalgia, headache, chills, or anosmia. A follow-up review was conducted with the care homes 7 days after testing. We conducted this assessment to determine whether anyone who tested positive for SARS-CoV-2 while asymptomatic subsequently developed any symptoms during this 7-day period. We sought to help differentiate between asymptomatic and presymptomatic positive cases.

In total, 388 individuals were tested (245 residents and 143 staff). Most residents tested were women (72\%). Those testing positive had a mean age of 86.4 years (SD, 8.05$)$. The most common comorbidities reported in the care-home residents were chronic neurological conditions and chronic heart disease. More than half of residents testing positive for SARS-CoV-2 reported having a chronic neurological condition such as dementia (55\%). Most staff members in the sample were women $(82 \%)$, and the mean age of staff members was 43.2 years old (SD, 18.3 years). Moreover, $~ 36 \%$ of the sample were smokers, none of whom tested positive for SARS-CoV-2. The most commonly reported comorbidities among

(c) The Author(s), 2020. Published by Cambridge University Press on behalf of The Society for Healthcare Epidemiology of America. This is an Open Access article, distributed under the terms of the Creative Commons Attribution licence (http://creativecommons.org/licenses/by/4.0/), which permits unrestricted re-use, distribution, and reproduction in any medium, provided the original work is properly cited. 